\title{
Proposta de aplicação do ABC - Sistema de Custeio Baseado em Atividades, numa empresa de serviços aduaneiros.
}

Proposed appropriation of ABC - System of Activity Based Costing, in a customs service company . Vladimir Afonso Paca Futi 1; Amélia Ferreira da Silva 2; José Manuel Pereira 3;

1 Vladimir Afonso Paca Futi, vladimirfuty@gmail.com, Angola, Faculdade de Economia da Universidade $11 \mathrm{de}$ Novembro

2 Amélia Ferreira da Silva, acfs@,iscap.ipp.pt, Portugal, Instituto Politécnico do Porto, ISCAP, CECEJ, CEPESE

3 José Manuel Pereira, jpereira@ipca.pt, Portugal Instituto Politécnico do Cávado e do Ave, ESG, CICF

\section{Resumo}

As empresas de prestação de serviços aduaneiros são os interlocutores oficiais entre a Administração Pública e o setor privado em todos os processos de importação e exportação de matérias-primas e mercadorias. No ambiente económico moderno, essas empresas procuram a melhoria contínua da qualidade dos serviços prestados e a eficiência dos processos que suportam esses serviços. Neste contexto, a informação detalhada sobre o custo destes serviços e sobre as atividades e processos que lhes estão subjacentes é essencial para a gestão de custos destas empresas.

No centro da metodologia ABC (Custeio Baseado nas Atividades) está a gestão de custos. Ao permitir calcular o custo das atividades, o ABC proporciona não só informação sobre os custos dos serviços/produtos mas também oportunidades de redução de custos e melhoria de processos numa lógica de criação de valor.

O objetivo deste trabalho é testar a aplicabilidade do ABC numa empresa de prestação de serviços aduaneiros e avaliar o contributo do $\mathrm{ABC}$ para a identificação de oportunidades de melhoria dos processos. Considerando este objetivo e a relação do investigador com a unidade de análise, foi seguida a metodologia investigação-ação.

Dada a complexidade de aplicação do modelo $\mathrm{ABC}$ original, foi sugerida a aplicação do Time Driven $A B C$ que, ao utilizar equações do tempo, se torna mais simples e menos dispendioso.

Palavras - Chave: Custeio Baseado em Atividades; Despachos Aduaneiros; Investigação-acção; Time Driven ABC.

\begin{abstract}
Those firms that provide customs services (Customs Brokers) are the valid interlocutors between the public authorities and the private sector regarding to the import and export processes of goods. In the modern economic environment, these companies look for continuous improvement of quality and efficiency of their internal processes and services. In such context, detailed information concerning the cost of the services provided, and the cost of the activities and processes that are behind them, is essential for cost management.

Cost management is at the center of the activity based costing (ABC). By informing managers about activities' costs, the $A B C$ provides not only information about how much each services costs but it also identifies cost reduction and process improvement opportunities within a logic of value creation.

The purpose of this work is to test the applicability of $A B C$ in providing customs services company and evaluate the potentialities of $A B C$ for the identification of process improvement opportunities. Considering the purpose of the work and researcher's relationship with the unit of analysis, it has been aplaied the research-action methodology. Take in account the complexity of the practical application of original $A B C$ model, it was suggested the application of Time Driven $A B C$, using equations time it becomes simpler and less expensive.
\end{abstract}

Key Words: Activity Based Costing; Customs Broker; Action-research;Time-Driven $A B C$. 


\section{I - Introdução}

Desde há muito que a capacidade de inovação é assumida como um fator de competitividade (Utterback e Abernathy, 1975). A essência de um modelo de negócio está na definição da maneira pela qual a empresa agrega valor aos clientes, seduz os clientes a pagar por esse valor e converte esses pagamentos para o lucro. É isso que suporta as hipóteses da gestão sobre o que os clientes querem, como querem e como a empresa se pode organizar para melhor atender a essas necessidades (Teece, 2010).

Ora, os sistemas de controlo de custos tradicionais tendem a basear-se na preservação do status quo e assumem o modo de fazer as coisas como um dado adquirido. Ao adoptar esta atitude, estas empresas desperdiçam um conjunto de oportunidades de melhoria e redução de custos que poderiam ser conseguidos através do aproveitamento do saber/conhecimento dos trabalhadores operacionais e da introdução de novos métodos de organização do trabalho. Nos sistemas tradicionais a ênfase é colocada na contenção de custos em vez de redução de custos. Contrariamente ao controlo de custos tradicional, a gestão de custos concentra-se na redução de custos, na melhoria contínua e na mudança, em vez de contenção de custos (Drury, 2012).

Mas, para gerir custos é imprescindível que esteja à disposição dos gestores informações relevantes sobre os custos da organização. Estas informações são fornecidas pela contabilidade de gestão, na apresentação de relatórios que auxiliam a gestão de custos. Quer seja para gerir ou para controlar custos, os sistemas de custeio são uma necessidade em qualquer tipo de empresa: seja ela comercial, industrial ou de serviços. Porém, a identificação de importantes limitações dos sistemas tradicionais levou ao surgimento de novas abordagens (Kaplan, 1984). Dentre as várias propostas de ferramentas de apoio à gestão de custos que surgiram nas últimas décadas no âmbito da contabilidade de gestão (Drury,2012), o Custeio Baseado em Atividades (ABC) e a Gestão Baseada nas Atividades (ABM) destacam-se ao nível da literatura (Cooper e Kaplan, 1988, Kaplan e Cooper, 1988; Kaplan e Atkison, 1998, Chapman, 2015).

No centro da metodologia ABC está a gestão de custos (Cokins, 1999). Mas, a redução de custos não pode ser vista como um objectivo em si mesma, é crucial que as iniciativas de redução de custos estejam estritamente ligadas à estratégia da empresa. Na verdade, existem três tipos de iniciativas de gestão de custos: as que reforçam a posição competitiva da empresa, aquelas que não têm impacto sobre a posição da empresa, e aquelas que enfraquecem a posição competitiva da organização (Cooper e Slagmulder, 2003). Estas últimas são, naturalmente, de evitar. Ao permitir calcular o custo das atividades, o ABC 
proporciona não só informação sobre os custos dos serviços/produtos mas também oportunidades de redução de custos e melhoria de processos numa lógica de criação de valor. Dada a importância das atividades onde se agregam valores aos clientes, pelo facto de serem consumidores de recursos da empresa, Ching (1995) afirmou que é importante apresentar mecanismos, de modo a assegurar a gestão dessas atividades. Estes mecanismos devem ser analisados e avaliados de forma a conduzi-las eficientemente para que atinjam três objetivos: diminuir custos, reduzir o tempo de duração e melhorar a qualidade.

Este trabalho pretende criar e desenvolver uma proposta de aplicação do Custeio Baseado em Atividades numa empresa de prestação de serviços aduaneiros angolana. Um dos investigadores é colaborador interno da empresa objecto de análise. Esta condição facilitou a primeira fase do diagnóstico pois, fazendo parte da área operacional onde se desenvolvem as actividades, e tenho conhecimento de que a empresa não possui atualmente um sistema de custeio formalizado, rapidamente percebeu a necessidade empresarial da implementação de um sistema de informação formal. Esta circunstância conjugou-se com a curiosidade académica dos investigadores e assim nasce um projecto que pretende não só resolver um problema concreto duma organização mas também criar uma oportunidade de reflexão crítica sobre a importância dos sistemas de informação de suporte à gestão de custos.

Este trabalho está organizado em 4 capítulos. Após a presente introdução é efetuada uma revisão da literatura sobre o ABC no capítulo II. Segue-se o capítulo III, onde além de justificar as opções metodológicas e os procedimentos adoptados, faremos a caracterização da empresa. No capítulo 4 é apresentado e discutido o modelo proposto. Finalmente, apresentam-se as principais conclusões do estudo.

\section{II - Fundamentos e evolução do Custeio Baseado em Atividades (ABC)}

$\mathrm{Na}$ segunda metade do século XX, particularmente a partir da década de $70 \mathrm{com}$ o advento da era do marketing, assiste-se ao esmorecimento dos princípios de gestão vigentes na era industrial e a alterações substanciais no interior das organizações e no seu contexto, trazendo consigo mudanças significativas, nomeadamente ao nível do conceito, da diversificação e da diferenciação do produto, o que provocou um aumento da importância relativa dos custos indiretos e dos custos não industriais no custo total dos produtos. Neste cenário, as insuficiências do método das secções homogéneas, quer enquanto método de valorimetria dos custos dos produtos, quer enquanto instrumento de controlo de gestão, foram-se tornando cada vez mais visíveis e denunciadas por académicos e profissionais. 
Além disso, a intensificação da concorrência global que se verificou nos anos de 1980 tornou mais prováveis e mais penosos os erros devidos à qualidade da informação sobre custos (Drury, 2012).

Segundo Holzer e Norreklit (1991), ao longo dos anos, o crescente custo de oportunidade de ter uma informação sobre custos de baixa qualidade, e a diminuição dos custos de operar sistemas de custos mais sofisticados, aumentou a procura por informação mais exata sobre os custos dos produtos. Assim, as críticas mais frequentes aos métodos tradicionais colocam-se ao nível da arbitrariedade a que está sujeita a imputação dos custos indiretos e no facto de apenas os custos de produção serem considerados, tornando este modelo insuficiente para efeitos de gestão. O método tradicional foi desenvolvido na era das grandes empresas industriais quando os custos diretos eram responsáveis por uma parte importante do custo de produção e por isso assume o volume de produção como o principal indutor de custos. Segundo Wang et al. (2010), este método em ambientes industriais modernos e de serviço distorce sistematicamente o custo dos produtos, uma vez que, os custos indiretos são uma parcela significativa. E na opinião de Gering (1999) o método tradicional tende a fornecer informações que, embora precisas muitas vezes chegam tardiamente por vezes irrelevantes e enganosas.

Desta forma, na segunda metade da década de 80, surge a proposta do método Activity Based Costing - ABC. Em termos muito gerais, podemos dizer que o $\mathrm{ABC}$ regista os custos das atividades para depois os imputar aos objetos de custo responsáveis por essas atividades: produtos, serviços, clientes. A principal ideia do ABC é a seguinte: as atividades consomem recursos e objetos de custo (produtos, serviços, clientes, fornecedores, etc.). $\mathrm{O}$ custo total de um objeto corresponde ao custo do produto de todos os recursos consumidos, por todas as atividades consumidas por esse objeto de custo. Desta forma, conforme Andrade et al., (1999) todos os custos tornam-se, essencialmente, em custos diretos e imputados, corretamente para seus respetivos objetos de custo.

$\mathrm{O} A B C$ veio reforçar e reafirmar a necessidade de imputar o custo ao seu objeto causal. A imputação dos recursos consumidos a cada atividade depende do tipo de recursos em causa e do seu carácter de direto ou indireto a uma determinada atividade. Por exemplo:

\begin{tabular}{|c|c|}
\hline Tipo de Custo & Método de imputação \\
\hline Custo da mão - de - obra & $\%$ do tempo despendido em cada atividade \\
Custo com o espaço ocupado & Espaço ocupado pelos pessoal que efetua a atividade \\
Custo com tecnologias de informação & Número de PC's por departamento \\
\hline
\end{tabular}

Fonte: Baseado em Mckenzie, 1999 
O passo seguinte consiste na identificação dos causadores dessas atividades (cost drivers) para depois as relacionar, se possível, com um produto, um serviço ou um cliente. Por exemplo:

\begin{tabular}{|c|c|}
\hline Atividade & Causa (driver) \\
\hline Introduzir uma encomenda no computador & Encomendas por cliente \\
Processar o retorno de mercadorias danificadas & Devoluções por produto \\
Montar e ligar uma máquina para iniciar a produção & Set-up por produto \\
Pesquisar informação sobre os clientes dos produtos & Pesquisa por produto/cliente \\
Pressionar os clientes com atraso no pagamento & Recebimentos atrasados por clientes \\
\hline
\end{tabular}

Pegando, por exemplo, nos custo relacionados com a atividade - pressionar os clientes com atraso no pagamento, segundo o método tradicional estes custos seriam provavelmente tratados como um custo geral não imputável, ou então, seriam distribuídos de igual forma por todos os clientes. O método $\mathrm{ABC}$ estabelece que estes custos deverão ser imputáveis somente aos clientes com atrasos no pagamento e apenas em função do número de vezes em que tais atrasos ocorreram.

Cooper e Kaplan (1988) definiram o método ABC como uma forma de resolver os problemas do sistema tradicional de gestão de custos; ou seja, os sistemas de contabilidade de custos convencionais eram muitas vezes incapazes de identificar corretamente os verdadeiros custos dos processos produtivos. Consequentemente, os gestores eram incapazes de tomar decisões sensatas ou fiáveis com base nos dados apresentados.

Embora não exista unanimidade completa quanto à origem deste método (Drury. 2012; Horngreen, 1993), todos os autores reconhecem a Jonhson e Kaplan, no seu trabalho "Relevance lost: The rise and fall of Management Accounting", publicado em 1987 pela Havard Business School Press, o mérito de terem desencadeado um debate a nível internacional sobre as insuficiências dos métodos tradicionais e de terem enunciado de forma sistematizada os princípios fundamentais do ABC. No mesmo ano, com a publicação do artigo de Cooper (1987), "Does your company need a new cost system? a divulgação do $\mathrm{ABC}$ conhece um novo impulso. Estes dois trabalhos foram seguidos por vários outros dos mesmos autores e despertaram a atenção de vários outros académicos. Com o entusiasmo gerado em volta do ABC, em 1992 já existia uma vasta literatura sobre o tema e os fundamentos e princípios do $\mathrm{ABC}$ estavam já consolidados. A passagem do $\mathrm{ABC}$ do mundo académico para o mundo empresarial, já iniciada no final da década de 80, começava a impor-se como uma realidade incontestável no início da década de 90, fruto, em grande parte, do trabalho das consultoras internacionais. 
No contexto empresarial, o ABC é apresentado como aliado da gestão, como um sistema desenvolvido para ir muito além do método tradicional, no sentido de melhorar a tomada de decisão nas empresas. Conforme Sheu et al., (2003) tem sido reconhecido como um instrumento que fornece informações de custo para sua verdadeira alocação. Os gestores não podem tomar decisões sem antes obterem informações confiáveis sobre os custos, por isso há a necessidade de calcular os custos dos produtos ou serviços através do Custeio Baseado em Atividades (Stefano et al., 2010).

O sistema de Custeio Baseado em Atividades (ABC) foi desenvolvido principalmente para atender às empresas industriais, mas desde os primeiros anos do seu desenvolvimento, decorreram estudos sobre a possibilidade de usá-lo também no setor dos serviços.

Portanto, a análise do ABC ilustra exatamente quais as atividades associadas ao negócio e como estão ligadas à geração de receitas e ao consumo de recursos. Cooper e Kaplan (1991) afirmaram que esta análise ajuda os gestores a tomar decisões que permitirão à empresa obter lucros.

$\mathrm{O} A B C$ fornece informações necessárias que permitem definir qual a melhor estratégia a ser adotada. A sua utilidade permite melhorar a qualidade das decisões estratégicas e operacionais. $\mathrm{O} A B C$ ajuda coletar informações úteis e indispensáveis para os gestores permite também identificar custos menores ou produtos de maior lucro. Segundo Sheu et al., (2003) estas informações fornecidas pelo ABC identificam também as áreas onde os custos são elevados bem como a não utilização dos recursos tendo em conta a capacidade da empresa. Portanto, a análise do ABC ilustra exatamente quais as atividades associadas ao negócio e como estão ligadas à geração de receitas e ao consumo de recursos. Cooper e Kaplan (1991) afirmaram que esta análise ajuda os gestores a tomar decisões que permitirão a empresa obter lucros.

A implementação do $\mathrm{ABC}$ é também um processo bastante estudado. Friedman e Lyne (1999) e Innes et al., (2000) desenvolveram estudos de caso longitudinais para explorar os fatores que influenciavam o sucesso verificado na sua implementação e descobriram que o sucesso estava associado a uma necessidade claramente reconhecida pelo ABC desde o seu surgimento, o amplo apoio dos gestores. Vazakidis et al., (2010) focalizou a sua atenção nas etapas da implementação do ABC:

- Reconhecimento de objetos de custo (a razão da análise de custo);

- Definir as atividades que afetam cada objeto de custo;

- Determinar as fontes de despesas que afetam cada atividade;

- Atribuindo as atividades para os objetos de custo e 
- Transferir o custo da atividade para os objetos de custo e argumentar sobre os resultados finais.

O custo das atividades, com este método, focaliza-se em objetos de custo (produtos, serviços e clientes). Uma atividade é um elemento de trabalho a ser executado para concluir um projeto, um processo ou operação que exige tempo e recursos associados (Narong, 2009). De acordo com Park e Simpson (2008), existem três diretrizes que permitem apoiar alocações de custos:

- Custos diretos imputados aos produtos: Os custos dos recursos incorporados num produto são imputados aos produtos. Incluem material direto e os custos de mãode-obra direta. Alguns dos custos relacionam-se com a capacidade e são utilizados exclusivamente por um único produto.

- Custos indiretos alocados aos produtos: Custos gerais dos recursos: custos gerais dos recursos ocorrem quando os recursos são consumidos por diversos produtos. Precisam ser alocados para os produtos. Normalmente, esses custos são coletados numa base anual do sistema de contabilidade;

- Centros de custo único do processo de atribuição de três etapas: usa centros de custo para alocar os custos de um grupo de recursos indiretos consumíveis necessários para operar os centros de custo. Os centros de custo incluem grandes máquinas de produção e recursos humanos;

- Custos de Atividade (centros de custo): geralmente consistem na utilização de custos de cada atividade de forma separada, se o custo ou a produtividade dos recursos for diferente e se o padrão da procura variar entre os recursos. Cada custo de atividade é homogêneo e tem uma relação de causa e efeito com o cost driver. A proliferação de vários produtos requer custos de atividade mais refinadas para refletir a complexidade da produção.

- Cost drivers de Atividade: os fatores de custo devem relacionar-se com a forma em que os custos de cada atividade são consumidos. Por exemplo, o custo de instalação é atribuído a um produto que consome uma configuração baseada em atividades de tempo de instalação se o tempo de configuração impulsionar os custos.

Mas, desde que surgiu o $\mathrm{ABC}$ tem sofrido vários desenvolvimentos, tendo sido enriquecido pelo contributo de vários autores nas mais diversas áreas. Turney (2012), por exemplo, identifica 4 gerações do ABC:

Figura 1. Gerações do ABC 


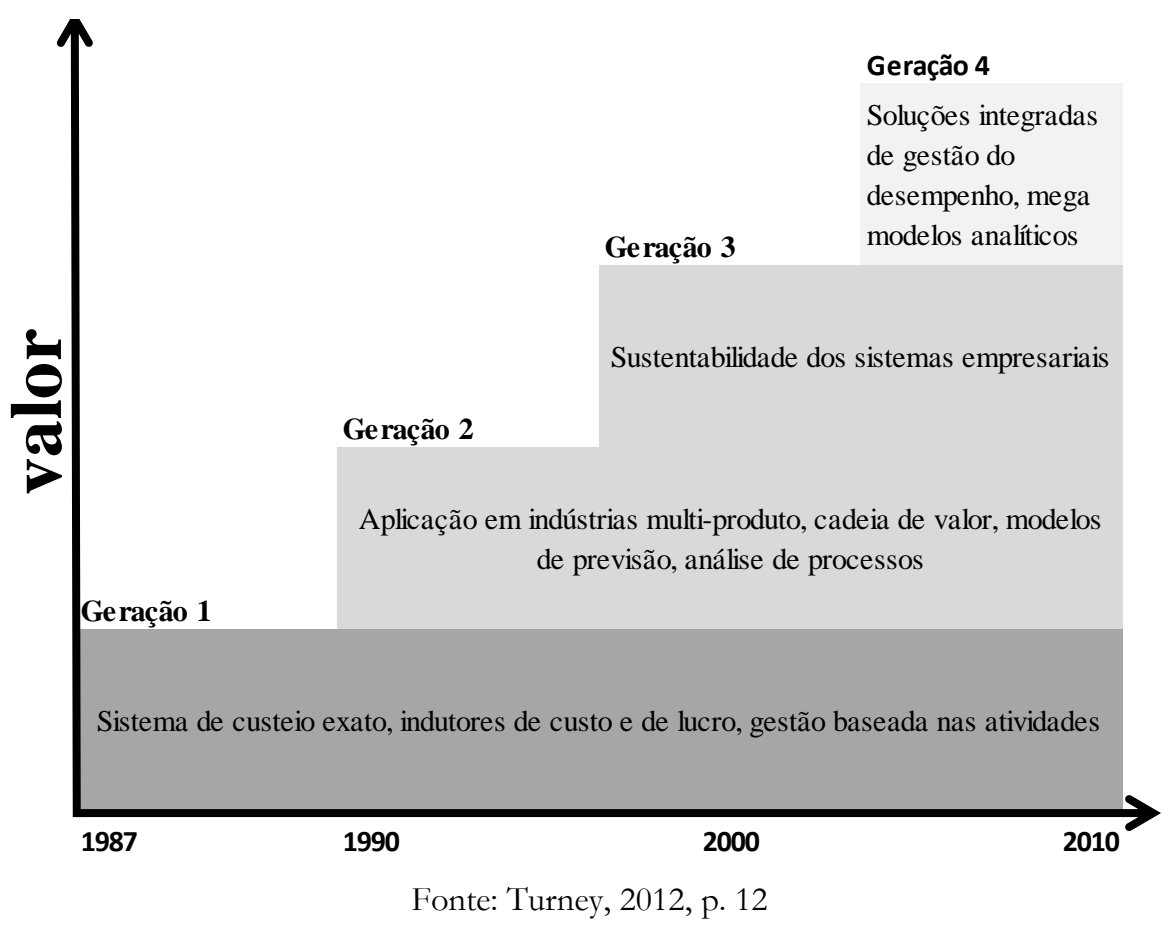

Além da sua evolução conceptual, a evolução do $\mathrm{ABC}$ tem sido enriquecido devido à sua aplicação integrado com outros instrumentos de contabilidade e controlo de gestão, nomeadamente EVA, Teoria das Restrições, Target Costing, Balanced Scorecard, ABM. Ching (2001) afirmou que, dada a essa complexidade verificada ao decidir o montante de recursos a ser aplicado em cada serviço ou em cada área, surgiu o ABM como alternativa uma vez que é o ABM é um processo que utiliza as informações fornecidas pelo ABC para gerir uma empresa e o $\mathrm{ABC}$ é um processo técnico que permite imputar os custos para as atividades e conduz essas atividades para produtos.

ABM operacional é sobre "como fazer bem as coisas", utilizando informações ABC para melhorar a eficiência. Aquelas atividades que agregam valor ao produto podem ser identificadas e melhoradas. As atividades que não agregam valor são aqueles que precisam ser reduzidos para cortar custos sem reduzir o valor do produto. O ABM estratégico é sobre "fazer as coisas certas", utilizando informações ABC para decidir quais os produtos, os clientes e as atividades a desenvolver, focando-se naqueles produtos, cliente e atividades de maior valor rentabilidade, relevância estratégica e valora acrescentado (Kaplan e Cooper, 1998). Ou seja, o ABM acontece quando os gestores apliquem os conhecimentos adquiridos com a aplicação do $\mathrm{ABC}$ e integrem esse conhecimento na tomada de decisões tanto no plano operacional como estratégico.

Simplificando, o ABM é ABC em ação (CIMA, 2001). A figura 2 retrata esta relação $\mathrm{ABC} / \mathrm{ABM}$ :

Figura 2. Relação ABC/ABM 


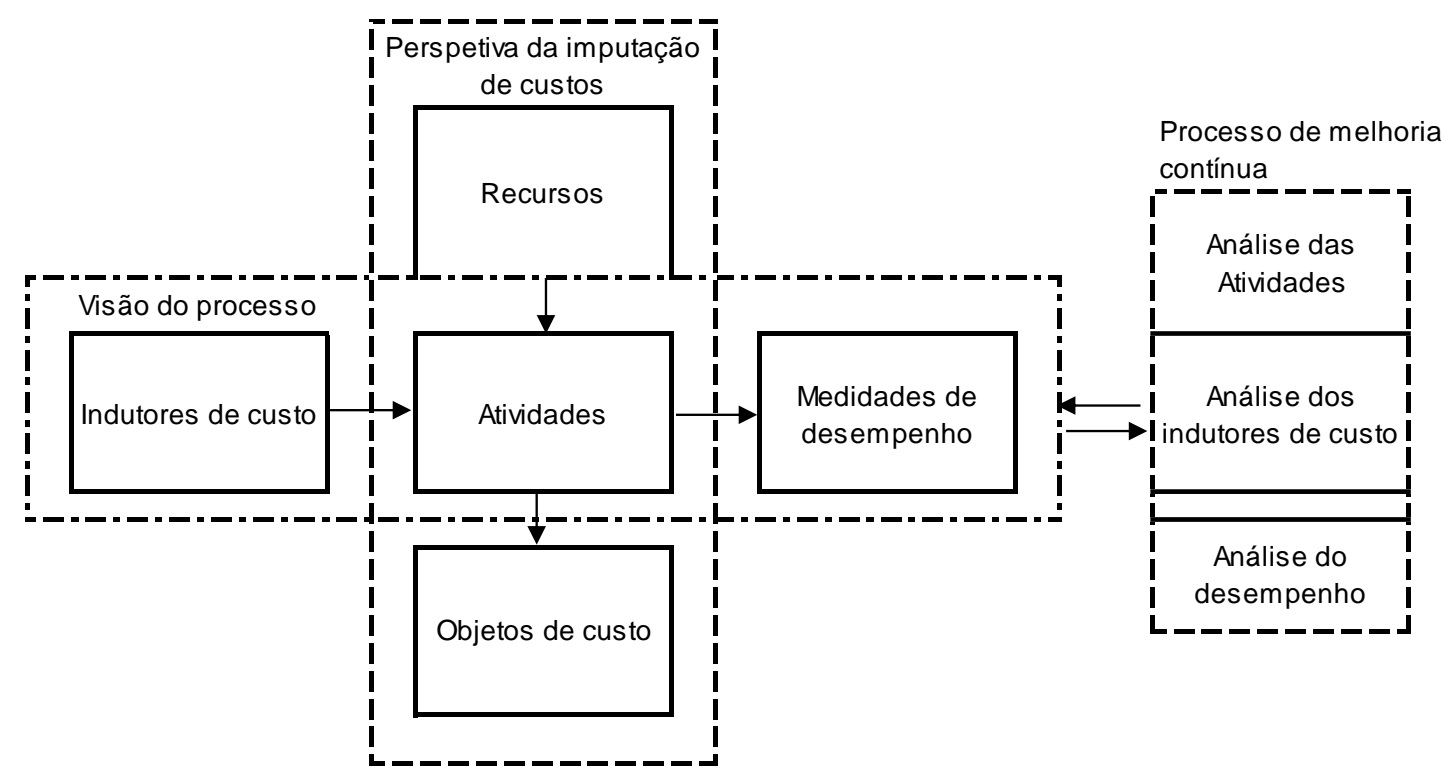

Fonte: Miller, 1996, p. 236

A literatura revela que o foco do $\mathrm{ABC}$ é fornecer informações precisas sobre o verdadeiro custo dos produtos, serviços, processos, atividades, canais de distribuição, clientes, contratos e projetos. Permitindo assim identificar problemas e traçar objetivos seguros que conduzam para soluções e oportunidades, através de informações financeiras e não financeira sobre as atividades e objetos de custo. Mas, e apesar de toda a argumentação favorável ao $\mathrm{ABC}$, os estudos sobre a aplicação do $\mathrm{ABC}$ não traduzem uma mensagem tão optimista. $\mathrm{Na}$ verdade, não podemos ignorar os argumentos dos mais céticos face ao contributo do ABC para o desempenho das organizações (Armstrong, 2002, Chapman, 2015). Szychta (2010), por exemplo, afirmou que apesar de uma proposta atraente, o ABC convencional não desfruta de aceitação universal, algumas empresas falharam na sua adoção, face às resistências comportamentais e organizacionais. Dada a dificuldade encontrada na adoção ou implementação do ABC tradicional, ou seja, da versão original do ABC, Kaplan e Anderson (2007) apresentaram um novo método como solução: o Time Driven Activity Based Costing (TDABC). Este método atribui os custos dos recursos diretamente aos objetos de custos (produtos, clientes ou serviços), por meio de um referencial simples que exige apenas dois conjuntos de estimativas, Primeiro calcula-se os custos de fornecimento da capacidade dos recursos, ou seja, identificam-se quais são os recursos necessários em cada etapa da operação para que as atividades sejam realizadas, como o pessoal, equipamentos e outros. Esse custo total é dividido pela capacidade - o tempo disponível dos empregados que efetivamente executam a atividade do departamento, de modo a determinar a taxa de custo da capacidade. Segundo, utiliza a taxa 
do custo da capacidade para distribuir os custos dos recursos de cada departamento entre os objetos de custo, estimando a procura de capacidade de recursos por cada item de objeto do custo.

De acordo com Kaplan e Anderson (2007), a abordagem Time driven evita o trabalho dispendioso, demorado e subjetivo de pesquisa de atividades do $\mathrm{ABC}$ convencional. $\mathrm{O}$ Time driven, como o nome sugere, utiliza o tempo para direcionar os custos dos recursos diretamente aos objetos de custo, como produtos, serviços e clientes. Deve-se calcular quantos dias por mês, em média, os empregados e máquinas trabalham, e em quantas horas ou em quantos minutos por dia os funcionários ou os equipamentos realmente estão disponíveis para a realização do trabalho, depois de subtrair os intervalos para repouso, treinamento, reuniões, manutenção, entre outros

Portanto, utilizam-se equações de tempo que oferecem aos gestores a possibilidade de simular o futuro. A metodologia capta os principais fatores que criam procura de capacidade de processo e na opinião de Kaplan e Anderson (2007), o modelo pode ainda ser incorporado com facilidade em um novo processo orçamentário que calcule de maneira analítica o fornecimento e o consumo de capacidade de recursos necessários para cumprir os planos de produção.

\section{III - Desenho do estudo}

\subsection{Metodologia}

O objetivo geral deste trabalho de investigação é elaborar uma proposta de aplicação do modelo de Custeio Baseado em Atividades (ABC) para uma empresa de prestação de serviços aduaneiros e simultaneamente avaliar o potencial do $\mathrm{ABC}$ enquanto instrumento de apoio à gestão de custos. Ora, considerando que a finalidade desta investigação é aplicar os ensinamentos que emergem da literatura na solução de um problema concreto, de uma organização específica, a metodologia qualitativa surge como uma inevitabilidade. $\mathrm{Na}$ verdade, dada a natureza do objectivo, podemos dizer que investigação-acção é uma "não opção" já que esta é a única abordagem de pesquisa que permite fazer observações profundas do processo da organização e exercer activamente uma influência sobre a organização.

O termo "pesquisa-ação" foi introduzido por Kurt Lewin, em 1946, para designar uma abordagem pioneira no âmbito da investigação social que combinava geração da teoria com a mudança do sistema social através do investigador que agia sobre ou no sistema social. $\mathrm{O}$ ato em si é apresentado como meio que permite simultaneamente mudar o sistema e gerar 
conhecimento crítico. Esta metodologia é indicada quando a finalidade da investigação é interpor-se, interferir na realidade estudada, para modificá-la.

Em termos genéricos, e segundo Tripp (2005), a investigação-ação corresponde a um processo que pretende aprimorar a prática, pela oscilação sistemática entre a ação no contexto de estudo e a investigação a respeito dela. "Planeia-se, implementa-se, descreve-se e avalia-se uma mudança para a melhora de sua prática, aprendendo mais, no correr do processo, tanto a respeito da prática quanto da própria investigação" (p. 445-446). Assim, uma investigação cujo objetivo é a solução de problemas "começa com a identificação do problema, o planeamento de uma solução, sua implementação, seu monitoramento e a avaliação de sua eficácia. (p446)"

$\mathrm{Na}$ área da contabilidade, a pesquisa intervencionista tem vindo a conquistar cada vez mais investigadores (Dumay, 2010, Jönsson e Lukka, 2006, Van Helden e Northcott, 2010), nomeadamente por se considerar que reduz o gap entre teoria e prática (Gummesson, 2000) e porque facilita e promove o uso de técnicas de contabilidade em novos contextos (Malmi e Granlund, 2009)

Esta investigação foi planeada por etapa. A primeira etapa, que é discutida neste artigo, compreende as fases de (i) Diagnóstico, (ii) Plano de Acão e (iii) Ação, sendo deixadas para uma segunda etapa da investigação as restantes duas das cinco fases identificadas por Susman e Evered (1978): (iv) Avaliar e (v) Especificação da aprendizagem. A figura 3 traduz a primeira etapa do processo de investigação:

Figura 3. Primeira etapa do processo de pesquisa

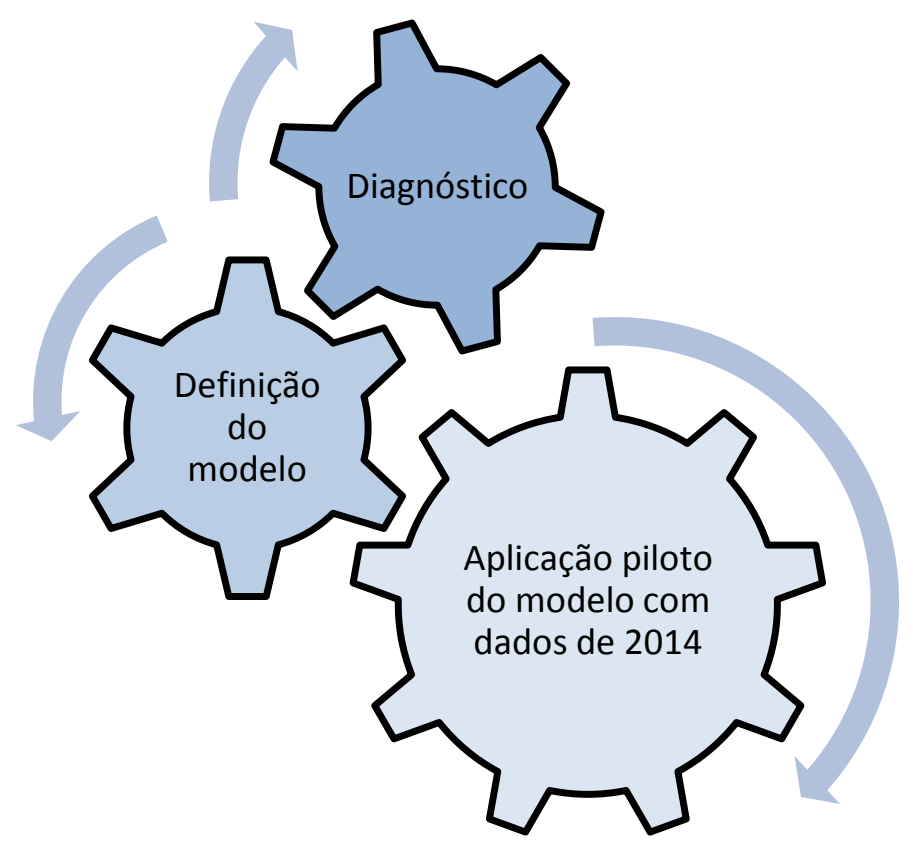

Fonte: Elaboração própria 
Ora, sendo esta uma investigação participativa, inspirada no paradigma do modelo investigação-ação, a primeira fase do projeto foi essencialmente de diagnóstico: conhecer a empresa, os seus serviços e processos de trabalho, a sua cultura, a sua estratégia empresarial e o seu sistema de informação. Nesta fase, recorremos essencialmente à análise documental, à observação e a reuniões informais com o responsável da empresa.

Posteriormente, e tendo como base as conclusões da fase anterior, iniciou-se o processo de desenho do modelo $\mathrm{ABC}$, o que neste caso corresponde basicamente à definição do plano de ação. Procedemos à recolha de dados sobre os processos de trabalho da empresa, recorrendo essencialmente a observações, análise documental e entrevistas aos trabalhadores. Foram ponderadas as diversas opções que iam surgindo para a definição do modelo, até chegar ao modelo final.

A última fase desta etapa da investigação correspondeu à aplicação do modelo. Começamos pela apresentação formal do modelo ao responsável da empresa e, utilizando os dados de 2014, foi feita uma aplicação piloto.

\subsection{Diagnóstico}

$\mathrm{Na}$ fase de diagnóstico foram consultados vários documentos, internos e externos à empresa, nomeadamente legislação, documentos que suportam os processos de trabalho e sítio de internet de autoridades oficiais. Foi feita uma visita geral à empresa e algumas observações dos processos de trabalho. Foi também realizada uma primeira reunião de trabalho serviu para informar o Despachante Oficial sobre o modelo ABC e ouvir as suas opiniões sobre a empresa e o seu contexto, conhecer os seus planos para o desenvolvimento do negócio, a empresa, e analisar a percepção que o Despachante tinha sobre o papel da informação contabilística para a tomada de decisão.

\subsubsection{Enquadramento sectorial}

A economia Angolana tem registado um aumento do seu comércio internacional, tendo inclusivamente apresentado uma Balança Comercial positiva nos últimos 5 anos. E embora o peso relativo do comércio do petróleo seja inegável, há também outros setores que começam a despertar e que têm contribuído para a afirmação da economia Angolana no mundo. Mas, para que esse crescimento seja sustentável, é necessário que os serviços associados à transação internacional de mercadoria sejam eficientes e promovam a eficiência dos seus clientes numa lógica de cadeia de valor. Ora, assim sendo, os serviços 
aduaneiros são uma componente importante do plano de internacionalização da economia Angolana.

A República de Angola, capital: Luanda, é um país africano situado na costa ocidental, cujo território é limitado a norte e a nordeste pela República Democrática do Congo, a leste pela Zâmbia, a sul pela Namíbia e a oeste pelo Oceano Atlântico. Anexa também o território de Cabinda, onde, através deste faz fronteira com a República do Congo, a norte.

Com uma população de mais ou menos 16 milhões de habitantes, o seu comércio baseia-se no seguinte; Agricultura: bananas, cana-de-açúcar, café, milho, algodão e gado; Industrias: petrolíferas e diamantíferas. Importações: maquinarias, veículos, medicamentos, etc. Exportações: crude, diamantes, café, algodão, etc. Maiores parceiros: Portugal, Brasil, Estados unidos da América, China e África do Sul.

De acordo com o Decreto-Lei n..$^{\circ}$ /06 de 4 de Outubro de 2011, as Alfândegas de Angola são um serviço executivo público que exerce a sua ação em todo território nacional. Como Instituição Pública do Estado, tutelada pelo Ministério das Finanças, as Alfândegas de Angola têm exercido um papel preponderante e de destaque na economia do país. Constituída por uma Administração Geral Tributária, cuja sede está em Luanda e com sete Regiões Tributárias distribuídas pelo país, designadamente: $1^{\mathrm{a}}$ Região Tributária, $2^{\mathrm{a}}$ Região Tributária, $3^{\mathrm{a}}$ Região Tributária, $4^{\mathrm{a}}$ Região Tributária, $5^{\mathrm{a}}$ Região Tributária, $6^{\mathrm{o}}$ Região Tributária e $7^{\text {a }}$; tem como compromissos:

- Prestar um serviço baseado na transparência e na eficácia;

- Salvaguardar os interesses do Estado através da cobrança dos direitos, fazendo cumprir a Legislação Aduaneira em vigor;

- Defender a sociedade do tráfico de mercadorias proibidas que possam representar um risco para a saúde, o ambiente, a moral e o património nacional;

- Cumprir com excelência os padrões de serviços prestados aos utentes, promovendo a concorrência leal, a redução de custos e a maior integração económica;

- Atuar sempre de forma justa e coerente, respeitando os direitos dos cidadãos;

- Assumir a responsabilidade pelas suas ações num ambiente de profissionalismo, honestidade e integridade.

No Portal de informação da Administração Geral Tributária (2015) estão claramente definidas todas as atividades aduaneiras e extra - aduaneiras.

Como em todos os países, em Angola é obrigatório o pagamento de impostos, resumidos em direitos aduaneiros e demais imposições, pela importação e exportação de mercadorias. Para além, das medidas e procedimentos adotados que simplificam, aceleram e dão 
transparência ao processo de desalfandegamento, as suas atividades dependem também da ação de outros intervenientes na cadeia do comércio externo, assim como do cumprimento voluntário e cabal das regras, por parte dos utilizadores dos serviços aduaneiros.

Segundo o Código Aduaneiro de Angola (2011) a ação das Alfândegas é condicionada pela intervenção de entidades, responsáveis pelas atividades extra - aduaneiras, requeridas em função do tipo de mercadoria, sendo: Ministério de Comércio, Interior (Polícia Fiscal, Económica e a DNIC), da Saúde, da Agricultura, da Relações Exteriores, da Indústria, dos Petróleos, dos Transportes (Concelho Nacional de Carregadores, Administração dos Portos e Aeroportos), Concessionárias dos Terminais Portuários, Empresas de Inspeções Pré-embarque, Transitários, Agências de Navegação e Despachantes Oficias.

Segundo Pacheco (2013), a figura de despachante oficial existe em Angola há muito tempo; por carta Régia de 16 de Fevereiro de 1784 criou-se uma Alfândega Regular em Luanda, referindo-se já a despachantes, o Regulamento da Alfândega da cidade de São Paulo de Loanda da auditoria do então governador Miguel António de Melo datado de 21 de Outubro de 1799, informa também embora indiretamente, o exercício das funções dos referidos despachantes nas suas relações com os oficiais alfandegários então existentes. A profissão, porém, só viria ser oficializada e o seu exercício regulamentado pelo Decreto $\mathrm{n}^{\mathrm{o}} 7$ de 7 de Dezembro de 1864, que definiu, pela primeira vez, as bases do regime a que ia ser subordinada a classe de despachantes.

O decreto n³1/105 de 15 de Janeiro de 1941 aprova o Estatuto Orgânico das Alfândegas Coloniais. Neste, o seu Capítulo XI do Título II é integralmente dedicado aos despachantes. A 29 de Setembro de 1960 publicou-se o Decreto nº48/199 que cria o novo estatuto Orgânico das Alfândegas. Este documento encontra-se ainda hoje em vigor e regulamenta, no seu Título $\mathrm{V}$, as pessoas que estão habilitadas para efetuarem despachos aduaneiros e o seu Capítulo II contém as disposições relativas a despachantes oficiais (Pacheco, 2013).

Em 1978, atendendo ao êxodo que atingiu generalizadamente todas as atividades nacionais é publicado o Despacho n⿳87A/78 do Ministério das Finanças, no qual se estipula o provimento de lugares de despachante e ajudante e precedido do mesmo de provas escritas, práticas e orais, cujos pró-formas são iguais aos que contém no estatuto orgânico de 1960. A 13 de Abril de 1979, pelo Decreto no 46 é extinta a Câmara dos Despachantes Oficiais de Angola, criada pela Portaria no6802, de 10 de Agosto de 1949 (Pacheco, 2013).

Em 1991, segundo (Pacheco, 2013) começou um processo de reorganização da classe, com a nomeação de novos despachantes e a posterior criação da Comissão Representativa dos 
Despachantes Oficiais. Considerando ser necessário dotar os despachantes oficiais de um órgão interlocutor e de orientação metodológica da respetiva atividade, bem como da defesa dos seus interesses em 7 de Abril de 1997, pelo Decreto $n^{\circ}$ 27, são aprovados os atuais estatutos da Câmara dos Despachantes Oficiais de Angola.

Porém, com a entrada das Alfândegas num sistema de modernização, em 2002, vários diplomas têm sido aprovados, incluindo o Código Aduaneiro de Angola (2011) que no seu artigo 36 liberaliza a profissão de Despachante Oficial, pode ser exercida em todo o território nacional.

A profissão de Despachante é exercida, em todos os postos aduaneiros, em regime de profissão liberal e de livre concorrência, não havendo limitações quanto ao número mínimo ou máximo de despachantes, podendo os despachantes licenciados pela Administração Geral Tributária exercer a sua atividade em todo território nacional (Código Aduaneiro de Angola, 2011).

De acordo com Ornelas (2011), em declarações à Angop (Agência de Noticias Angolanas), à margem de uma palestra subordinada ao tema "a importância do Despachante Oficial no contexto geral da cobrança de impostos no país", em alusão ao $14^{\circ}$ aniversário da câmara, Angola conta com 235 Despachantes Oficiais, dos quais 132 trabalham na província de Luanda.

Portanto, os Despachantes Oficiais de Angola e seus ajudantes, de acordo com o Código Aduaneiro de Angola (2011) constituem os interlocutores privilegiados entre a Administração Aduaneira e os Agentes Económicos ligados ao comércio internacional, no que concerne à atividade de prestação de serviços, podem praticar em nome dos seus representados os atos relacionados com o despacho aduaneiro de bens ou de mercadorias, inclusive de bagagem de viajante, transportados por qualquer via, na importação ou exportação, a principal função do Despachante Oficial é a formulação da Declaração Aduaneira de importação e exportação, que nada mais é do que a proposição do destino a ser dada aos bens submetidos ao controlo aduaneiro, indicando o regime aduaneiro a aplicar às mercadorias e ao comunicar os elementos exigidos pela Alfândega para a aplicação desse regime.

\subsubsection{Caraterização da unidade de análise}

A XPTO iniciou a sua atividade no ano 2005, em Luanda, com a prestação de serviços aduaneiros e dispõe de delegações nas regiões de Soyo, Cabinda e Lobito. Do ponto de 
vista jurídico trata-se duma empresa em nome individual, o que significa que o empresário responde solidariamente pelas dívidas e obrigações decorrentes da atividade empresarial. A XPTO tem 40 funcionários sendo 25 do sexo masculino e 15 do sexo feminino. De acordo com a estrutura organizacional apresentada abaixo a empresa XPTO tem um modelo centralizado onde a autoridade máxima é o Despachante Oficial.

A empresa tem uma estratégia de especialização na actividade de emissão de Despachos Aduaneiros. Um Despacho Aduaneiro é a execução de formalidades necessárias para o Desembaraço Fiscal de Mercadorias. Pelo que os tipos de despachos produzidos constituem os objetos de custos finais. Existem quatro tipos de despachos produzidos pela empresa: despacho normal, despacho especial, despacho de cabotagem e despacho de trânsito internacional:

- Despacho normal: submissão junto das Alfândegas é feita sem a aplicação dos códigos de tratamento disponíveis e corre apenas no regime estabelecido por lei, como por exemplo: regime 11 (Importação Definitiva) ou regime 21 (Exportação definitiva);

- Despacho especial: submissão junto das Alfândegas é feita mediante a aplicação dum código de tratamento, como por exemplo: 11/600 e 11/850, o primeiro aplica-se quando se trata duma mercadoria perigosa e que carece dum desalfandegamento urgente, podem ser aceites no ato da sua submissão junto das Alfândegas, apenas as cópias dos documentos utilizados na transação, o despachante compromete - se dentro do prazo estipulado por lei fazer a regularização do mesmo, isto é, fazendo a entrega dos documentos originais. No segundo isto é 11/850, trata - se duma importação incompleta, isto é o despacho é submetido faltando alguns documentos;

- Despacho de cabotagem: é feito apenas para o transporte de mercadorias internamente por via marítima, ou seja mercadorias desalfandegas no porto de Luanda cujo destino ou a utilização final será em Cabinda

- Despacho de Trânsito internacional: feito quando se utiliza o território angolano apenas para a passagem de mercadorias provenientes de um país para outro, por exemplo mercadorias provenientes da República Democrática do Congo passam por Angola, cujo destino final é a Zâmbia ou Namíbia.

De um modo geral o sistema de informação de apoio à gestão é bastante rudimentar. Importa ressaltar que a empresa não possui contabilidade financeira organizada pois 
não é legalmente obrigada a isso. Consequentemente, a informação que existe é essencialmente informação para a gestão e controlo financeiro da actividade. Contudo, como não há um modelo formalizado, esta informação é recolhida, tratada e apresentada de modo ad-hoc. O Despachante Oficial responsável pela XPTO reconhece que haveria vantagens em alterar esta realidade, introduzindo novos modelos que fossem compreendidos por todos e que permitisse identificar a origem dos custos e principalmente as oportunidade de melhorar em termos de produtividade.

A figura 4 descreve a cadeia logística de uma transacção internacional, de modo que se possa compreender a importância da empresa em estudo e a posição assumida por ela, no comércio internacional: 


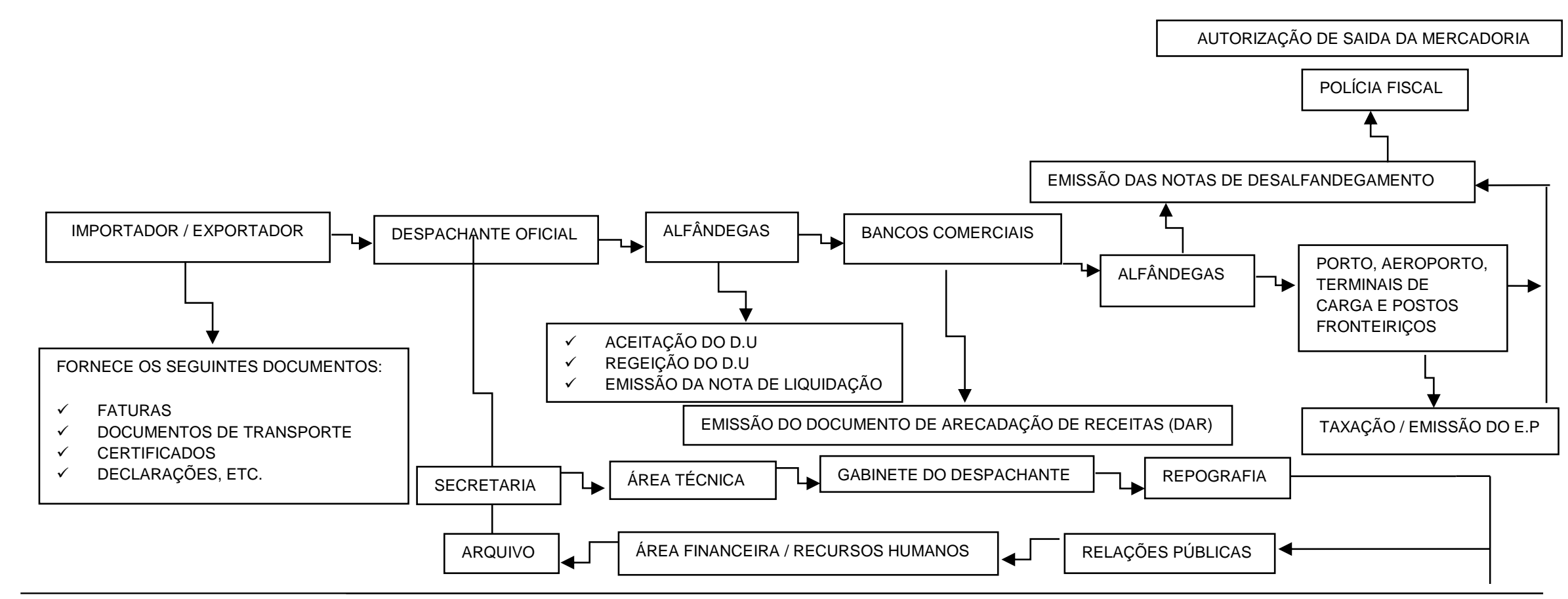

Fonte: Elaboração Própria 


\subsection{Definição do plano de ação}

O modelo ABC matricial apresenta recursos, atividades, indutores de custo e objetos de custo, através da matriz recurso-atividade e matriz-produto, está assente no cálculo matricial e é indispensável para ser utilizado quando se trata de pequenas e médias empresas de prestação de serviço permitindo gerar informações relevantes tendo em conta o processo de tomada de decisão.

Para garantir a sua efectiva implementação seguimos as recomendações de Roztock et al., (1999): (i) recolhemos toda a informação sobre os recursos necessários, (ii) identificamos as principais actividades (iii) construímos a matriz recurso-atividade (permite saber que tipo de recursos é que cada atividade consome), (iv) determinamos os coeficientes dos indutores de recurso e fizemos a representação percentual na matriz recurso-atividade, (v) construímos a matriz atividade-produto (vii) determinamos os coeficientes dos indutores de atividades e representamos a relação percentual da atividade com o produto na matriz atividade-produto e por fim (viii) determinamos a matriz produto.

$\mathrm{Na}$ tabela que se segue identificamos as principais actividades por área funcional:

Tabela 1. Lista da atividades

\section{Processo}

Secretaria

Área Técnica

Gabinete do Despachante Oficial

Reprografia

Relações Públicas

Área financeira

Arquivo

\section{Atividade}

1. Registo de novos Clientes

2. Registo de entrada e saída do processo

3. Distribuição dos processos aos contabilistas

4. Analise Documental

5. Classificação Pautal das Mercadoria

6. Contabilização do Despacho Aduaneiro

7. Preparação do Despacho Aduaneiro

8. Verificar o Despacho Aduaneiro

9. Assinatura do Despacho Aduaneiro

10. Carimbo do Despacho Aduaneiro

11. Contratação de pessoal

12. Fazer a cópia do Despacho Aduaneiro

13. Transporte do Despacho Aduaneiro

14. Submissão do Despacho Aduaneiro

15. Requisição de Fundos

16. Elaboração das folhas salários

17. Colocar na pasta e arquivar o Despacho Aduaneiro

A secretaria é responsável pelo recebimento dos documentos indispensáveis para a realização dum despacho aduaneiro, registo de entradas de correspondência, prestação de 
informações, etc. Já a área técnica é praticamente o setor chave para o funcionamento duma Banca de Despachos Aduaneiros, neste setor trabalha o ajudante e os Contabilistas Aduaneiros, responsáveis pela preparação dos despachos, dotados de conhecimento sobre a legislação aduaneira, algumas vezes acabam sendo os verdadeiros despachantes.

O Despachante Oficial, representante da Banca, é a pessoa habilitada para junto das Alfândegas intervir no desembaraço aduaneiro de mercadoria. É portador duma cédula que lhe confere os direitos de exercer a atividade aduaneira, proprietário da Banca e que tem como tarefa verificar e analisar os despachos aduaneiros antes da sua submissão nas Alfândegas. Responsável pelo controlo e contratação do pessoal.

Após a verificação, assinatura e carimbo por parte do Despachante Oficial, este envia o Despacho Aduaneiro para a reprografia de modo que se faça a cópia do mesmo e o devolve para o contabilista que o preparou.

A área de relações públicas responde pelos assuntos externos da Banca, tais como: pagamento da conta de eletricidade, telefone, água, internet, compra de material de escritório, requisição de formulários, livros de registros, acompanhamento de clientes, solicitação de novos clientes, marketing da empresa, etc. A sua principal missão dentro da banca é transportar e submeter junto das Alfândegas o Despacho Aduaneiro.

A área financeira calcula os honorários inerentes ao serviço prestado pela Banca a um cliente, é controla todos os pagamentos e recebimentos.

De acordo com a legislação angolana, todos os despachos aduaneiros feitos são válidos por um período de cinco anos, pelo que é indispensável por parte Despachantes Oficiais arquivarem as cópias de todos os documentos utilizados para o desembaraço aduaneiro de mercadorias. Por exemplo, quando o Despacho Aduaneiro é aceite nas Alfândegas, este emite a nota de liquidação e em função da nota de liquidação o Despachante Oficial prepara a requisição de fundos e a entrega juntamente com a nota de liquidação ao importador para que este pague a dívida aduaneira e os honorários mediante o serviço prestado, os honorários são depositados na conta do Despachante. Ao passo que a dívida é paga diretamente na Instituição Bancária autorizada para o efeito, concluída esta operação, a Alfândega emite a nota de desalfandegamento ou de remoção em caso de mercadorias que necessitam ser acompanhadas e inspecionadas. O trabalho do Despachante termina quando as Alfândegas emitem a nota de Desalfandegamento ou Remoção.

Depois de definidas as actividades, e mesmo antes de calcular o respectivo custo, foi ponderada a opção entre o ABC tradicional e o Time-driven ABC. A opção final recaiu sobre o TD-ABC depois de consideradas as seguintes questões: sendo um serviço de mão- 
de-obra intensiva, o tempo revelava-se como o um indutor mais ajustado à maioria das actividades; o baixo nível de informatização da empresa dificultava a recolha de dados sobre outros indutores, aumentando assim o custos de manutenção do modelo, o TD-ABC facilitava a identificação do tempo ocioso das diversas actividade, respondendo assim a um dos objectivos do projecto.

Uma vez assumida a opção pelo TD-ABC, foram estudados os tempos das diversas actividades. A partir das observações e das entrevistas realizadas foi possível aferir os tempos que se apresentam na tabela 2.

Tabela 2. Tempo gasto em cada atividade

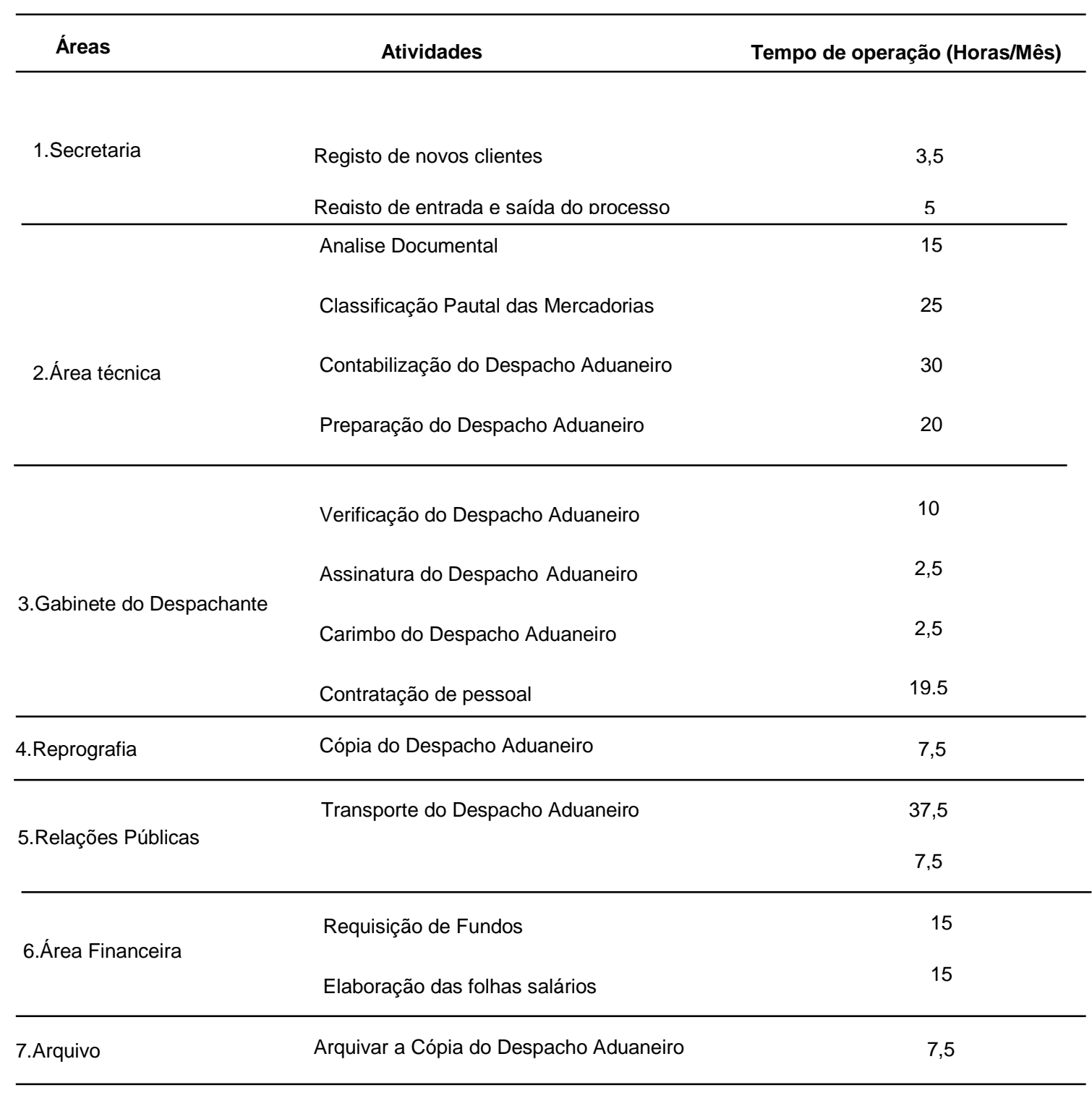

Importa salientar que, um dos grandes lemas apresentado pelo Despachante Oficial na busca de novos clientes, tem a ver com a rapidez no processo de desalfandegamento de 
mercadorias, pelo que, o fator tempo é um recurso a ter em conta, quanto menos tempo o processo demorar maior será a satisfação do cliente.

Apresentadas as atividades e funções dos funcionários, os recursos, o tempo indispensável para a realização de cada atividade estamos agora em condições de elaborar as matrizes. Os coeficientes de matrizes apresentados na tabela 3 foram obtidos a partir do indutor de recurso selecionado, neste caso o tempo que cada recurso consome na realização de cada atividade dividido pelo tempo total consumido por cada recurso.

Tabela 3. Matriz Recurso - Atividad

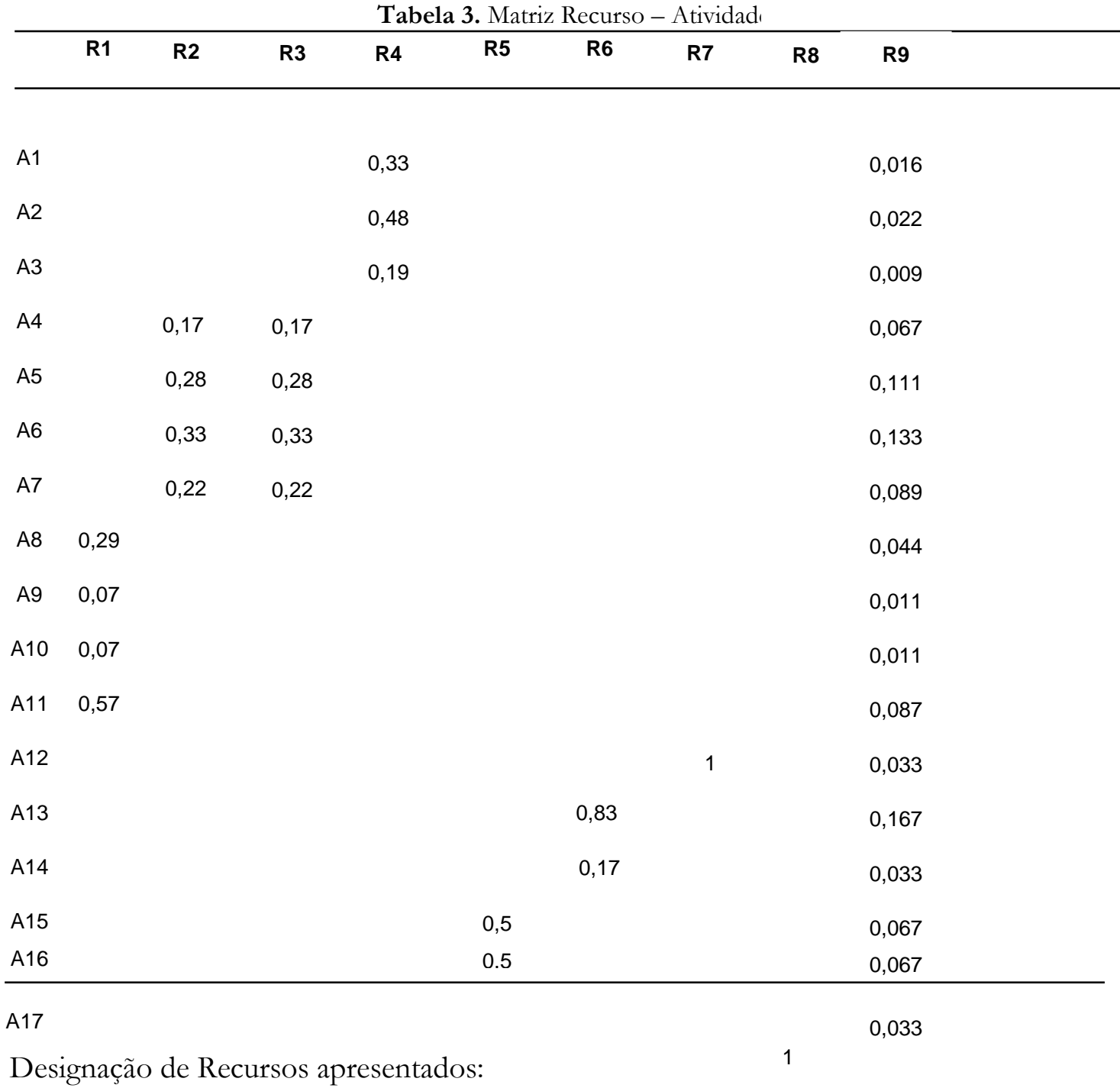

R1 - Despachante Oficial; R2 - Ajudante Despachante; R3 - Contabilistas Aduaneiros; R4 - Pessoal da secretaria; R5 - Pessoal da Área financeira; R6 - Estafetas; R7 - Pessoal da Reprografia; R8 - Pessoal do Arquivo e R9 - Equipamento Administrativo + Software + Matérias Consumidas + Instalações 
Em termos de percentagem na tabela 4, verifica-se que o Recurso 3 (Contabilista Aduaneiro) é consumido 17\% pela atividade 4 (analisar os documentos); 28\% pela atividade 5 (classificar em termos pautais as mercadorias); 33\% pela atividade 6 (Contabilizar o Despacho Aduaneiro de Mercadorias) e 22\% pela atividade 7 (Preparar o Despacho Aduaneiro). O total de todos os coeficientes por cada recurso da empresa é igual a 1; o que em termos percentuais corresponde à 100\%.

Tabela 4. Matriz Recurso

\begin{tabular}{cccccccccc}
\hline $\mathbf{R} 1$ & $\mathbf{R 2}$ & $\mathbf{R} 3$ & $\mathbf{R 4}$ & $\mathbf{R 5}$ & $\mathbf{R 6}$ & $\mathbf{R 7}$ & $\mathbf{R} 8$ & $\mathbf{R 9}$ & Total \\
\hline $18.000,00$ & $14.760,00$ & $9.840,00$ & $5.904,00$ & $5.904,00$ & $3.936,00$ & $3.936,00$ & $3.936,00$ & $64.220,00$ & $\mathbf{1 3 0 . 4 3 6 , 0 0}$ \\
\hline $14 \%$ & $11 \%$ & $8 \%$ & $4,5 \%$ & $4,5 \%$ & $3 \%$ & $3 \%$ & $3 \%$ & $49 \%$ & $100 \%$
\end{tabular}

Tabela 5. Matriz atividade

\section{Custo Total de cada atividade}

\begin{tabular}{|c|c|c|}
\hline $\mathrm{A} 1$ & $2.975,84$ & $2 \%$ \\
\hline $\mathrm{A} 2$ & $4.246,76$ & $3 \%$ \\
\hline A3 & $1.699,74$ & $1 \%$ \\
\hline A4 & $8.484,74$ & $6,5 \%$ \\
\hline A5 & $14.016,42$ & $11 \%$ \\
\hline A6 & $16.659,26$ & $13 \%$ \\
\hline A7 & $11.127,58$ & $8,5 \%$ \\
\hline A8 & $8.045,68$ & $6 \%$ \\
\hline A9 & $1.966,42$ & $1,5 \%$ \\
\hline A10 & $1.966,42$ & $1,5 \%$ \\
\hline A11 & $15.847,14$ & $12 \%$ \\
\hline A12 & $6.055,26$ & $5 \%$ \\
\hline A13 & $13.991,62$ & $11 \%$ \\
\hline A14 & $2.788,38$ & $2 \%$ \\
\hline A15 & $7.254,74$ & $5,5 \%$ \\
\hline A16 & $7.254,74$ & $5,5 \%$ \\
\hline \multirow[t]{2}{*}{ A17 } & $6.055,26$ & $5 \%$ \\
\hline & $130.436,00$ & $100 \%$ \\
\hline
\end{tabular}


Para construir a tabela 5 (Matriz Atividade), primeiramente foi preciso agrupar todos os custos suportados, representados pela Matriz Recurso e o total dessa matriz deve ser igual ao total da Matriz atividade, ou seja, a tabela 3 (Matriz recurso - atividade) multiplicado pela tabela 4 (Matriz Recurso) é igual a tabela 5 (Matriz Atividade). A tabela 6 apresenta a produção por actividade, com referência ao ano de 2014.

Tabela 6. Produção por atividade

\begin{tabular}{llc}
\hline Atividades & Serviços/Produto & № de Clientes registados \\
\hline 1.Registo de novos clientes & Despacho Normal & 10 \\
& Despacho Especial & 20 \\
& Despacho de Cabotagem & 2 \\
& Despacho de Trânsito Internacional & 1 \\
\hline & & № de Processos registados \\
& Despacho Normal & 1.000 \\
& Despacho Especial & 3.000 \\
& Despacho de Cabotagem & 500 \\
& Despacho de Trânsito Internacional & 200 \\
\hline & & № de Processos distribuídos \\
& Despacho Normal & 1.000
\end{tabular}

№ de Documentos Analisados

\begin{tabular}{|c|c|c|}
\hline \multirow{4}{*}{ 4.Análise Documental } & Despacho Normal & 4.000 \\
\hline & Despacho Especial & 12.000 \\
\hline & Despacho de Cabotagem & 2.000 \\
\hline & Despacho de Trânsito Internacional & 800 \\
\hline
\end{tabular}

№ de Mercadorias classificadas

5.Classificação Pautal de Mercadoria

$\begin{array}{lr}\text { Despacho Normal } & 3 \\ \text { Despacho Especial } & 2 \\ \text { Despacho de Cabotagem } & 1 \\ \text { Despacho de Trânsito Internacional } & 1\end{array}$

3

2

1

1 
№ de Despachos Contabilizados

\begin{tabular}{|c|c|c|}
\hline \multirow{4}{*}{ 6.Contabilizar o Despacho } & Despacho Normal & 1.000 \\
\hline & Despacho Especial & 3.000 \\
\hline & Despacho de Cabotagem & 500 \\
\hline & Despacho de Trânsito Internacional & 200 \\
\hline
\end{tabular}

№ de Despachos Preparados

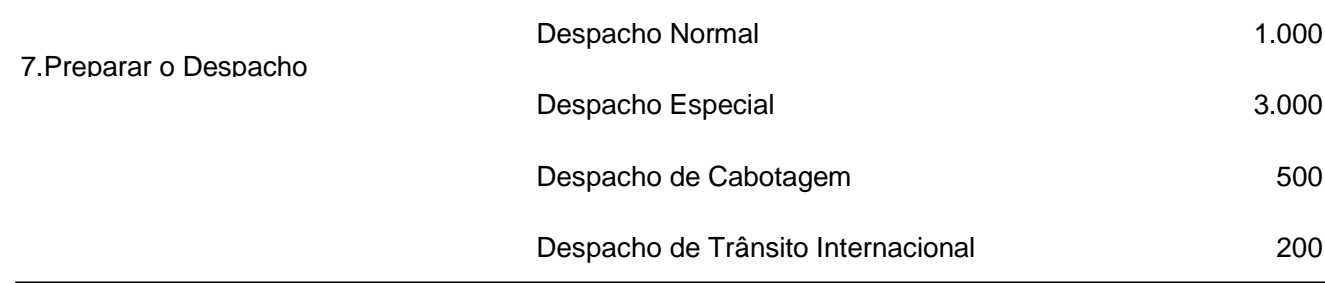

№ de Despachos verificados

Despacho Normal

1.000

8.Verificar o Despacho

Despacho Especial

3.000

Despacho de Cabotagem

500

Despacho de Trânsito Internacional

200

№ de Despachos assinados

\begin{tabular}{|c|c|}
\hline \multirow{4}{*}{ 9.Assinar o Despacho } & Despacho Normal \\
\hline & Despacho Especial \\
\hline & Despacho de Cabotagem \\
\hline & Despacho de Trânsito Internacional \\
\hline
\end{tabular}

№ de Despachos carimbados

10.Carrimbar o Despacho

Despacho Normal

1.000

Despacho Especial

3.000

Despacho de Cabotagem

500

Despacho de Trânsito Internacional

200

№ de Pessoas contratadas

11.Contratar Pessoal

Despacho Normal

1

Despacho Especial

1

Despacho de Cabotagem

0

Despacho de Trânsito Internacional

0

№ de Cópias feitas

\begin{tabular}{|c|c|c|}
\hline \multirow{4}{*}{ 12.Fazer cópia do Despacho } & Despacho Normal & 1.000 \\
\hline & Despacho Especial & 3.000 \\
\hline & Despacho de Cabotagem & 500 \\
\hline & Despacho de Trânsito Internacional & 200 \\
\hline
\end{tabular}

E3 - Revista de Economia, Empresas e Empreendedores na CPLP | Volume 1 | Número 2 


\begin{tabular}{|c|c|c|}
\hline \multirow{4}{*}{ 13. Transportar o Despacho } & Despacho Normal & 1.000 \\
\hline & Despacho Especial & 3.000 \\
\hline & Despacho de Cabotagem & 500 \\
\hline & Despacho de Trânsito Internacional & 200 \\
\hline
\end{tabular}

№ de despachos submetidos

\begin{tabular}{|c|c|c|}
\hline \multirow{4}{*}{ 14.Submeter o Despacho } & Despacho Normal & 1.000 \\
\hline & Despacho Especial & 3.000 \\
\hline & Despacho de Cabotagem & 500 \\
\hline & Despacho de Trânsito internacional & 200 \\
\hline
\end{tabular}

№ de Requisições Feitas

15.Requisitar Fundos

$\begin{array}{lr}\text { Despacho Normal } & 1.000 \\ \text { Despacho Especial } & 3.000 \\ \text { Despacho de Cabotagem } & 500 \\ \text { Despacho de Trânsito Internacional } & 200\end{array}$

№ de Folhas elaboradas

16.Elaborar Folhas de salário

$\begin{array}{lc}\text { Despacho Normal } & 3 \\ \text { Despacho Especial } & 3 \\ \text { Despacho de Cabotagem } & 3 \\ \text { Despacho de Trânsito Internacional } & 3\end{array}$

№ de Cópias arquivadas

17.Arquivar a cópia do Despacho

Despacho Normal
Despacho Especial
Despacho de Cabotagem
Despacho de Trânsito Internacional

1.000

3.000

500

200

Para a determinação o volume de atividades foi preciso observar o número de repetições verificadas em cada atividade necessárias para a realização dum determinado serviço. Assim, por exemplo na atividade $17 \mathrm{o} \mathrm{n}^{\circ}$ de cópias do P2 $=3.000$

$\mathrm{Na}$ matriz atividade - serviço, cada elemento é a proporção do indutor de atividade relacionado com o produto correspondente. Para o seu cálculo é necessário dividir o indutor de atividade relacionado com o produto pelo total da quantidade de indutores de atividade, pelo que; para este trabalho considerou-se os seguintes indutores. 
Tabela 7. Matriz Atividade - Serviço

\begin{tabular}{lccccccccccccc}
\hline & A1 & A2 & A3 & A4 & A5 & A6 & A7 & A8 & A9 & A10 & A11 & A12 & A13 \\
\hline P1 & 0,30 & 0,21 & 0,25 & 0,21 & 0,43 & 0,21 & 0,21 & 0,21 & 0,21 & 0,21 & 0,50 & 0,21 & 0,21 \\
P2 & 0,61 & 0,64 & 0,25 & 0,64 & 0,29 & 0,64 & 0,64 & 0,64 & 0,64 & 0,64 & 0,50 & 0,64 & 0,64 \\
P3 & 0,06 & 0,11 & 0,25 & 0,11 & 0,14 & 0,11 & 0,11 & 0,11 & 0,11 & 0,11 & 0,00 & 0,11 & 0,11 \\
P4 & 0,03 & 0,04 & 0,25 & 0,04 & 0,14 & 0,04 & 0,04 & 0,04 & 0,04 & 0,04 & 0,00 & 0,04 & 0,04 \\
\hline & A14 & A15 & A16 & A17 & & & & & & & & & \\
P1 & 0,21 & 0,21 & 0,25 & 0,21 & & & & & & & & & \\
P2 & 0,64 & 0,64 & 0,25 & 0,64 & & & & & & & & & \\
P3 & 0,11 & 0,11 & 0,25 & 0,11 & & & & & & & & & \\
P4 & 0,04 & 0,04 & 0,25 & 0,04 & & & & & & & & & \\
\hline
\end{tabular}

\subsection{Aplicação piloto do modelo}

O modelo desenvolvido no ponto anterior recolhe contribuições do $\mathrm{ABC}$ matricial e do Time Driven. O primeiro permite clarificar a relação entre atividades, recursos e serviços. Baseia-se na multiplicação de matrizes e tem várias vantagens, como por exemplo, permite que os custos de cada atividade sejam facilmente identificados, bem como alguns ajustes que podem ser introduzidos, como resultado de mudanças que possam ocorrer na prestação de serviços. O segundo facilita o trabalho de identificação e cálculos dos indutores pois assume o tempo como indutores comuns às diversas atividades.

Aplicando o nosso modelo aos dados de 2014, elaboramos um relatório interno, destinado ao gestor da empresa. O conteúdo desse relatório é sumariamente apresentado de seguida. Considerando as quatro tipologias de serviços ao cliente (P1 = Despacho Normal, P2 = Despacho Especial, P3 = Despacho de Cabotagem e P4 = Despacho de T. Internacional) como objeto de custo final, a tabela 8 mostra o custo total por tipo de serviço em 2014.

Tabela 8. Custo total por serviço

\begin{tabular}{ccccc}
\hline P1 & P2 & P3 & P4 & Total \\
\hline $35.697,00$ & $72.773,00$ & $14.130,00$ & $7.836,00$ & $130.436,00$ \\
\hline $27 \%$ & $56 \%$ & $11 \%$ & $6 \%$ & $100 \%$
\end{tabular}

Ao cruzarmos esta informação com as respectivas receitas (neste caso equivalente a proveitos pois o prazo médio de recebimento é zero), torna-se evidente que o despacho especial é o serviço com maior rentabilidade. 
Figura 6. Comparação entre custos e receitas

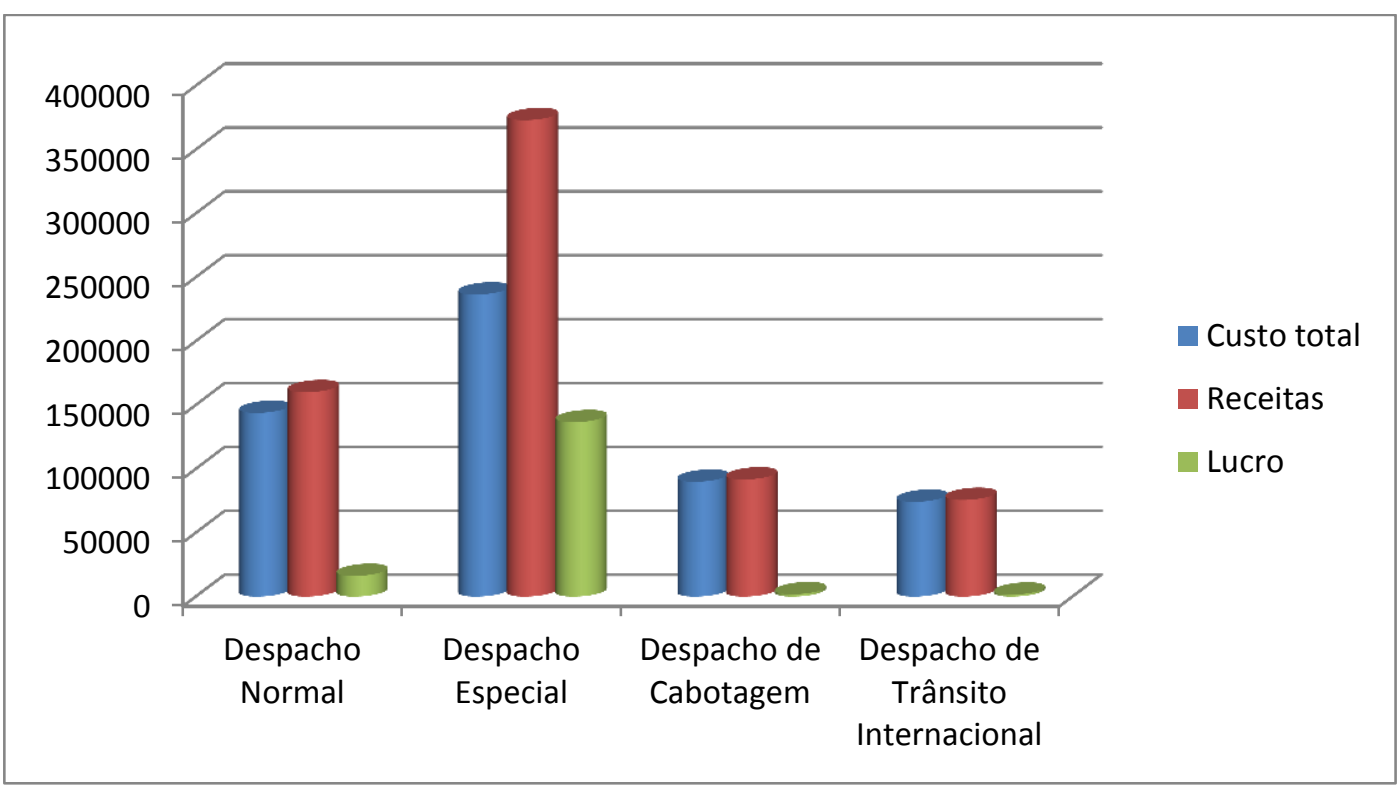

A figura 6 evidencia o fato da Sociedade Nacional de Distribuição dos Combustíveis de Angola (SONANGOL) ser o maior cliente, e por sinal o mais rentável, por causa dos Despachos especiais de exportação de Petróleo Bruto (Crude), donde provêm a maior parte das receitas e lucros da empresa.

Em termos de produtividade e eficiência, constata-se que a área técnica apresenta indícios de desperdício de recursos conforme evidenciado na tabela 8 .

Tabela 8. Cálculo da Ociosidade por Departamento

\begin{tabular}{|c|c|c|c|c|c|}
\hline Departamentos & Total de funcionários & Horas/mês & T/estimado & Ociosidade & $\%$ \\
\hline Secretaria & 4 & 42 & 42 & 0 & 0 \\
\hline Área Técnica & 15 & 1.350 & 360 & 990 & 73 \\
\hline G. do Despachante & 1 & 34,5 & 138 & $-103,5$ & -3 \\
\hline Reprografia & 4 & 30 & 30 & 0 & 0 \\
\hline Relações Públicas & 8 & 360 & 180 & 180 & 50 \\
\hline Área Financeira & 4 & 120 & 120 & 0 & 0 \\
\hline Arquivo & 4 & 30 & 30 & 0 & 0 \\
\hline
\end{tabular}


Há um tempo ocioso relevante no departamento da Área Técnica de 73\%, pelo fato de ser a área chave da empresa, ou seja, é neste departamento onde os despachos aduaneiros são produzidos pelos contabilistas. Já a ociosidade no departamento do Despachante Oficial é negativa, porque tudo que se faz na banca passa por ele. Seria um erro considerar uma produtividade à $100 \%$. Mas uma solução possível para baixar a ociosidade seria a redução dos recursos humanos em determinadas áreas. Contudo, esta opção só deve ser tomada depois de ponderados potenciais efeitos colaterais.

\section{IV - Discussão do modelo e considerações finais}

$\mathrm{O}$ método $\mathrm{ABC}$ é defendido como um bom instrumento de gestão, assumindo-se como uma ferramenta de análise e controlo na prestação de informações que auxiliam aos gestores na tomada de decisões estratégicas de uma organização.

No método $\mathrm{ABC}$ afirma-se que as atividades são consumidas pelos produtos e elas, por sua vez, consomem os recursos da empresa. O ABC ou custeio baseado em atividades pressupõe que nas empresas não se geram custos mas sim atividades. E, esse consumo pode ser explicado através dos indutores de custo. No ABC pretende-se que a relação entre o centro de custo e o indutor seja verdadeira. Por esta razão, o sistema ABC é tido como complexo por exigir muita informação e neste sentido, no presente projecto optamos pelo Time Driven ABC. Assim, foram definidas as equações de tempo que, de maneira direta e automática, distribuem recursos de custo das atividades executadas e as transações processadas.

Neste estudo, o objetivo principal consistia em aplicar o Custeio Baseado em Atividades numa empresa de prestação de serviços aduaneiros e para tal fez-se a seguinte pergunta: ao ser aplicado na empresa, como pode o ABC contribuir para o seu melhoramento?

No início do mês de junho, o modelo desenvolvido foi apresentado formalmente ao Gestor da empresa numa reunião onde foram expostos de forma organizada todos os pressupostos do modelo, a informação que era utilizada para a sua aplicação e os resultados obtidos. Fornecemos ao Gestor um relatório do trabalho.

De um modo geral a apreciação do trabalho desenvolvido foi bastante positiva e os comentários do Gestor deixaram claro que o modelo era percebido como uma mais-valia para a empresa. O Gestor comentou que era seu desejo implementar um sistema de contabilidade financeira e contabilidade de gestão na empresa, e que os resultados deste trabalho o encorajavam a isso. Mostrou também alguma surpresa quanto à rentabilidade de alguns serviços tendo dito que no futuro iria averiguar essa rentabilidade, pois isso 
permitia-lhe uma seleção dos clientes e prioridades mais racional e lucrativa. Também foi bastante comentada a ociosidade de algumas atividades, um assunto que tinha passado despercebido até então mas que o Gestor quer analisar em mais detalhe no sentido de futuramente aumentar o nível de produtividade dos recursos disponíveis. Finalmente importa realçar que desde o início este projeto contou com o apoio do Gestor da empresa e que, no início do nosso trabalho, o sistema de informação contabilístico da empresa era bastante rudimentar.

O estudo realizado identificou que o lucro obtido pela empresa tendo em conta os seus serviços prestados está diretamente ligada ao valor da mão-de-obra, o que justifica uma proporção elevada em termos de custos diretos. A grande dificuldade encontrada foi no sentido de determinar o tempo das atividades, uma vez que cada serviço prestado pela empresa utiliza as mesmas atividades consumindo insumos distintos, aumentando a necessidade de tempo e investimento para um estudo mais aprofundado e criterioso. Porém não se deixou de atingir o objetivo do trabalho, de aplicar o método $\mathrm{ABC}$ na empresa de prestação de serviços aduaneiros.

O grande contributo deste trabalho foi desenvolver um sistema que permitiu ao Gestor saber realmente quais são os custos reais verificados e relacionar esses custos com os lucros ou receitas, bem como saber ou conhecer a produtividade da empresa que só foi possível graças ao método aplicado.

Quanto à efetiva aplicação do modelo proposto na empresa que analisamos temos algumas reservas pois, apesar da reação positiva do responsável da empresa, não podemos ignorar que atualmente a empresa em estudo tem um sistema de informação muito rudimentar, pelo que, a opção pela aplicação do modelo proposto constituiria uma mudança significativa. Ora, as mudanças na contabilidade de gestão raramente ocorrem no vácuo. Geralmente ocorrem em simultâneo com as mudanças na estratégia de negócio da empresa ou outras mudanças organizacionais, particularmente as que afetam a distribuição do poder de decisão e a avaliação de desempenho ou do sistema de recompensa. Com efeito, as alterações na arquitetura organizacional das empresas, incluindo as mudanças no sistema de contabilidade, muito provavelmente ocorrem em resposta a mudanças na estratégia de negócios da empresa causada por choques tecnológicos e mudanças das condições de mercado. (Zimmerman, 2011)

Assim, e não obstante a perspetiva positiva sobre o potencial valor acrescentado do trabalho desenvolvido, não nos foi possível aferir se o novo sistema era ou não utilizado na tomada de decisões. Na verdade, sendo uma aplicação piloto, com dados históricos, não 
houve ainda a oportunidade de retirar ensinamentos consistente sobre a adequabilidade do modelo proposto, os problemas que surgem, a sua efectiva adopção e utilização na tomada de decisão e o seu contributo para a mudança da organização. Por isso, este projecto terá de ser encarado como uma primeira etapa dum projecto que terá continuidade no futuro.

Ora, tal como Chapman e Kern (2012), partilhamos da ideia chave de que o propósito do sistema de custeio é suportar a tomada de decisão e não simplesmente existir enquanto sistema. Deste modo, o efetivo contributo deste projeto para a empresa só poderá ser avaliado numa fase posterior.

Além disso, existe o risco de este projeto cair na armadilha do paradoxo $A B C$ (Gosselin, 2007), ou seja, depois de um entusiamo inicial com o ABC, segue-se uma fase de desilusão à medida que os benefícios prometidos se revelam difíceis de alcançar e o custo de manutenção do sistema se apresenta alto (Chapman, 2015).

\section{Referências}

- Andrade, R.C. Pessanha Filho, A.M. Espozel, L.O.A. Maia, R.Y., Qassim. (1999). Activity Based costing for production learning. Int. J. Production Economic, 62 (1), 175-180.

- Armstrong, P. (2002). The costs of activity-based management. Accounting, Organizations and Society, 27(1-2), 99-120.

- Chapman, C. (2015). Researching accounting in health care: considering the nature of academic contribution. Accounting and Finance, 55, 397-413

- Chapman, C. S., and Kern, A. (2012). Reflections on the research and practice of costing. Irish Accounting Review, 19(1/2), 23-29.

- Ching, H.Y. (1995). Gestão baseada em custeio por atividades = ABM - Activity Based Management. São Paulo: Atlas, 1995.

- Ching, H.Y. (2001). Gestão Baseada em Custeio por Atividades. São Paulo: Atlas, 2001

- CIMA (2001). Technical Briefing. Activity-based Management - An Overview. London: CIMA.

- Código Aduaneiro de Angola. Decreto-Lei n. ${ }^{\circ}$ 5/06 de 4 de Outubro, 2011.

- Cokins, G. 1999. Using ABC to become ABM. Journal of Cost Management, (January/February): 29-35.

- Cooper, R. (1987). Does your company need a new cost system? Journal of Cost Management, Summer, 45-491 
- Cooper, R. and Slagmulder, R. (2003). Strategic cost management: Expanding scope and boundaries. Journal of Cost Management, (January/February): 23-30

- Cooper, R., and Kaplan 1988. Implementing an activity - based cost system. Journal of Cost Management 4 (1), 33 - 42.

- Drury, C. (2012). Management and Cost Accounting. Cengage Learning EMEA, $8^{\text {th }}$ edition, United Kingdom, ISBN-13: 9781408064313.

- Dumay, J. (2010). A critical reflective discourse of an interventionist research project. Qualitative Research in Accounting \& Management, 7(1), pp. 46-70.

- Friedman, A., Lyne, S. (1999). Success and Failure of Activity-based Techniques: a Longterm Perspective. CIMA Publishing.

- Gering, M. (1999). Activity based costing and performance improvement. Management Accounting, 77 (3), 24-26.

- Gosselin, M. (2007). A review of activity-based costing: Technique, implementation and consequences. in: C.S. Chapman, A. G. Hopwood, M. D. Shields, eds., Handbook of Management Accounting Research (Elsevier, Amsterdam), 641-671.

- Gummesson, E. (2000). Qualitative Methods in Management Research, 2nd ed., Sage, London.

- Holzer, P. and Norreklit, H. (1991). Some thoughts on cost accounting developments in the United States. Management Accounting Research. 2 (1), 3-13.

- Horngreen, C., Datar, S. and Rajan, M. (2011). Cost Accounting. A Managerial Emphasis. Prentice Hall, 14th Edition

- Innes, J., Mitchell, F. and Sinclair, D. (2000). Activity-based costing in the UK's largest companies: a comparison of 1994 and 1999 survey results. Management Accounting Research, 11 (3), 349 - 362.

- Johnson, H. and Kaplan, R. (1987). The Rise and Fall of Management Accounting. Management Accounting, 68 (7), 22-30.

- Jönsson, S. and Lukka, K. (2006). There and back again: doing interventionist research in management accounting., in Chapman, C.S., Hopwood, A.G. and Shields, M.D. (Eds), Handbook of Management Accounting Research, 1, 73-397

- Kaplan, R. (1984). The Evolution of Management Accounting. The Accounting Review, 54(3), 390-418.

- Kaplan, R. and Atkison, A. A. (1998). Advanced Management Accounting. 3th edition, Prentice Hall International Editions. 
- Kaplan, R. and Cooper, R. (1998). Cost and effect: Using integrated cost systems to drive profitability and performance. Boston: Harvard Business School Press.

- Kaplan, R. S., and Cooper, R (1988). Measure cost right; make the right decisions. Harvard Business Review, 66 (5), 96-103.

- Kaplan, R.S., and Anderson, S.R. (2007). Time-driven activity-based costing a simpler and more powerful path to higherprofits. Boston, MA: Harvard Business School Press.

- Malmi, T. and Granlund, M. (2009), In search of management accounting theory. European Accounting Review, 18(3), 597-620.

- Miller, J A (1996). Implementing activity-based management in daily operations. London: J Wiley.

- Narong, D. K. (2009). Activity-based costing and management solutions to traditional shortcomings of cost accounting. Cost Engineering, 51(8), 11-18.

- Neto, N. (2012). Procedimentos Aduaneiros de Importação de Mercadorias. Seminário sobre Operações Cambiais - BNA.

- Ornelas, M. (2011). Angola conta com mais de 200 Despachantes Oficiais. Página consultada em < www.portalangop.co.ao/Angola/.

- Pacheco, J. (2013). Queremos acabar com a confusão entre Despachante e Transitário. Jornal Agora <agora.co.ao/Agora/Artigo/28672.

- Park, J., and Simpson, T. W. (2008). Toward an activity-based costing system for product families and product platforms in the early stages of development. International Journal of Production Research, 46(1), 103-105. http://dx.doi.org/10.1080/00207540600825240

- Portal das Alfandegas de Angola (2015), "Publicações". Página consultada em 21 de Janeiro de 2015, < http://www.alfandegas.gv.ao/publicacoes4.aspx?tipo id=91>.

- Roztocki, Narcy, Valenzuela, Jorge F., Porter, Jose D., Monk, Robin M and Needy, Kim LaScola. (1999). A procedure for smooth implementation of activity based costing in small companies. Proceeding of the 1999 American Society of Enginnering Management (ASEM), National Conference. Virgin Beach, Outubro 21-23, 279 288.

- Sheu, C., Chen, M.H., and Kovar, S. (2003). Itegrating ABC and TOC for better manufacturing decision making. Integrated Manufacturing Systems, 14(5), 433-441.

- Stefano NM, Godoy LP, Casarotto Filho N., and Santa CA (2010). Uma proposta de gestão de custos em pequenas organizações de serviço utilizando o Activity Based Costing. Revista ABCustos, 5(2), $01-28$. 
- Susman, G.I. and Evered, R.D. (1978). An assessment of the scientific merits of action research. Administrative Science Quarterly, 23(4), 582-603.

- Szychta, A. (2010). Time-driven activity-based costing in service industries. Social Sciences/Socialiniai mokslai, 67 (1), 49-60.

- Teece, D. (2010). Business Models, Business Strategy and Innovation. Long Range Planning, 43, 172-194.

- Tripp, D. (2005). Pesquisa-ação: uma introdução metodológica. Educação e Pesquisa, $31(3), 443-466$

- Utterback, J. and Abernathy, W. (1975). A Dynamic Model of Process and Product Innovation. OMEGA, The Int. J1 of Mgmt Sci., VoI. 3, No. 6

- Van Helden G.J., Aardema H., Ter Bogt H.J. and Groot T.L.C.M. (2010). Knowledge creation for practice in public sector management accounting by consultants and academics: preliminary findings and directions for future research. Management Accounting Research, 21(2), 83-94.

- Vazakidis A, Karagiannis I, and Tsialta A (2010). Activity-based costing in the public setor. Journal of Social Sciences, 6 (3), 376-382.

- Wang, P., Du, F., Lei, D., and Lin, T. W. (2010). The choice of cost drivers in activity-based costing: Application at a Chinese oil well cementing company. International Journal of Management, 27 (2), 367-373.

- Zimmerman, J. (2011). Accounting for Decision Making and Control, $7^{\text {th }}$ Ed., Irwin McGraw-Hill, New York. 